$\underline{\text { Research article }}$

\title{
The impact of a hand hygiene workshop on improving the knowledge of hand hygiene of medical students
}

\author{
NP Senanayake ${ }^{1}$, V Navaratne $^{1}$, A Balasuriya $^{1}$ \\ Sri Lankan Journal of Infectious Diseases 2019 Vol.9 (2):103-110 \\ DOI: http://doi.org/10.4038/sljid.v9i2.8241
}

\begin{abstract}
Introduction and Objectives: Knowledge of hand hygiene is important for medical students. The aim of this study was to compare the knowledge before and after a workshop on hand hygiene held for medical students at the Faculty of Medicine, General Sir John Kotelawala Defence University, Sri Lanka.

Methods: A self-administered, pre-tested validated questionnaire, based on hand hygiene guidelines of the World Health Organization (WHO), was distributed among the medical students before and after conducting a workshop on hand hygiene.Results were assessed by comparing the current guidelines set by the WHO with the knowledge of hand hygiene among the medical students.
\end{abstract}

Results: All 177 students participated in the study before conducting the workshop. There were 104 (58.8\%) preclinical and $73(41.2 \%)$ clinical students. Of the 104 preclinical students, the percentage who knew the importance of "My five moments for hand hygiene" approach (hand hygiene before direct contact with patients, after direct contact with patients, before clean/aseptic procedures, after contact with blood/body fluid and after contact with patient's surrounding) before conducting the workshop were $53.8 \%, 67.3 \%, 51.0 \%, 88.5 \%$ and $34.6 \%$ respectively. Of the 73 clinical students, the percentage who knew the importance of the "My five moments for hand hygiene" approach before conducting the workshop were $49.3 \%, 63.0 \%, 87.7 \%, 94.5 \%$ and $27.4 \%$ respectively. Of the 112 students who participated in the workshop, there were $68(60.7 \%)$ preclinical and $44(39.3 \%)$ clinical students. Of the 68 preclinical students, 77.9\%, 79.4\%, 91.2\%, 95.6\% and 70.6\% knew the importance of the "My five moments for hand hygiene" approach post workshop. Post workshop, the percentage of the 44 clinical students who knew the importance of "My five moments for hand hygiene" approach were 90.9\%, $88.6 \%, 93.2 \%, 97.7 \%$ and $81.8 \%$ respectively.

Conclusions: The pre workshop knowledge of hand hygiene among the two categories of medical students was not satisfactory. The knowledge on each component of "My five moments for hand hygiene" concept improved to more than $70 \%$ after conducting the workshop.

Key words: Hand hygiene, Hospital acquired infections, Health care workers

${ }^{1}$ General Sir John Kotelawala Defence University, Sri Lanka

Address for correspondence: Dr Nilanthi Senanayake, Department of Microbiology, Faculty of Medicine, University of Colombo, Sri Lanka. Telephone: +94777598995 Email: nilanthisenanayake@yahoo.com

https://orcid.org/0000-0002-6413-5559

Received 20 March 2019 and revised version accepted 5 July 2019

(c) (7)

distribution, and reproduction in any medium, provided the original author and source are credited.

SLJID • www. http://sljol.info/index.php/SLJID • Vol. 9, No. 2, October 2019 


\section{Introduction}

Hospital-acquired infections (HAIs) are a major public health problem all over the world, particularly in developing nations. ${ }^{1}$ Several studies have shown the role of healthcare workers' (HCWs) hands in the transmission of micro-organisms in healthcare institutions, resulting in the spread of hospital acquired infections. $^{2}$ Patients colonized with nosocomial pathogens contaminate their immediate surroundings resulting in contamination of HCWs hands when handling the patients or their immediate surroundings during routine care activities. It has been shown that these organisms are capable of surviving on HCWs' hands for several minutes following contamination. Therefore, hand hygiene is vital in the prevention of HAIs.

In institutions where hand hygiene practices are not carried out or are suboptimal, direct and indirect transmission of nosocomial infections occur in patients. ${ }^{3}$ Therefore, hand hygiene is an important healthcare issue and is the single most cost effective and practical measure to reduce the incidence of HAIs. ${ }^{4,5}$ However, studies have shown that rates of compliance with hand hygiene practices are low in most hospitals and overall compliance rates are below 50\% and as a result, HAIs have become increasingly common. ${ }^{6}$ Consequently, multi drug resistant pathogens such as methicillin resistant Staphylococcus aureus (MRSA) have become increasingly reported during the past two decades, especially in developing countries. ${ }^{7}$ Continuous efforts are being made to identify effective and sustainable strategies to increase hand hygiene compliance. One such effort is the introduction of an evidence-based concept of "My five moments for hand hygiene" by the World Health Organization (WHO). The "My 5 Moments for Hand Hygiene" approach defines five key moments when health-care workers should perform hand hygiene.

These five moments include the moment before touching a patient, before performing aseptic and clean procedures, after being at risk of exposure to body fluids, after touching a patient, and after touching patient surroundings. This concept has been used to improve hand hygiene among healthcare workers. ${ }^{8,9}$ A study from Saudi Arabia conducted in 2012 concluded that the knowledge of hand hygiene among medical students was insufficient and that serious efforts are needed to improve the knowledge and practices of hand hygiene among medical students. ${ }^{10}$ A study which was conducted at a Turkish medical school in 2010 indicated that the knowledge and practices of hand hygiene among the medical students was insufficient. ${ }^{11}$ Another study conducted at the Hannover Medical School, Germany in 2010 before students entered the clinical phase showed that their knowledge on correct indications of hand hygiene was lacking. ${ }^{12}$ Although the prevalence of health care associated infections is high in the Asian region, there is a paucity of studies exploring this subject in this region. ${ }^{13-16}$ Hence, WHO's concept of "My five moments for hand hygiene" was made the basis of the present study to evaluate the knowledge of hand hygiene among military medical students at the General Sir John Kotelawala Defence University, Sri Lanka.

Health education, by conducting workshops on hand hygiene is one possible way to improve knowledge and practices of hand hygiene among health care workers, including medical students. The objectives of the present study therefore was to ascertain pre and post workshop knowledge of hand hygiene among two categories of medical students (preclinical and clinical) in the Faculty of Medicine, General Sir John Kotelawala Defence University (KDU), Sri Lanka and to determine whether participating in a workshop on hand hygiene improved hand hygiene knowledge in each category. 


\section{Methods}

This study was a descriptive cross-sectional study carried out at the Faculty of Medicine, General Sir John Kotelawala Defence University (KDU) in September 2013. Ethical approval for the study was obtained from the Ethical Review Committee, Faculty of Medicine, KDU.

A self-administered, pre-tested questionnaire based on the hand hygiene guidelines laid down by the World Health Organization ${ }^{17}$ was used for data collection. The questionnaire was administered in English. and distributed after a brief explanation. Students were given 15 minutes to answer the questionnaire. It was explained to the students that participation is voluntary and that there will be no repercussions for not participating in the study. The students were requested to hand over the completed questionnaire to the Department of Para Clinical Sciences to ensure confidentiality. The questionare was given to all medical students at KDU ( $\mathrm{n}=177)$ before the workshop.

Thereafter, a one-day workshop on hand hygiene which consisted of lectures on hand hygiene (introduction to hand hygiene, indications for hand washing, surgical implications of hand hygiene and technique of hand hygiene) and practical demonstrations of hand washing was conducted for a total of 112 students. The same questionnaire was distributed 2 weeks after the workshop among all the students who attended the workshop.

Results were assessed by comparing the current guidelines set by the World Health Organization (WHO) with the knowledge of hand hygiene among these medical students. ${ }^{2}$ The following questions were analysed. Hand hygiene is the single most important event in the prevention of hospital acquired infections, indications for My Five Moments for Hand Hygiene (hands should be washed before having direct contact with patients, after having direct contact with the patients, before clean/ aseptic procedures, after contact with body fluid/ excretion/ blood/ mucus membranes/ non-intact skin/ wound dressings, after contact with any object in patient's immediate surroundings), hands should be washed when moving from a contaminated body site to a clean body site in the same patient, duration of hand washing and the need for further education in hand hygiene. The percentages were calculated and compared using the $\mathrm{z}$ test for proportions. A p value of less than 0.05 was statistically significant.

\section{Results}

All 177 students to whom the questionnaires were distributed participated in the pre-test before the workshop on hand hygiene. Of the students, 132 (74.6\%) were males. There were $104(58.8 \%)$ preclinical students and $73(41.2 \%)$ clinical students. Less than one-third of preclinical (28.8\%) and clinical (34.2\%) students knew that hand washing is the single most important event in the prevention of hospital acquired infections before conducting the workshop but there was no statistically significant difference between the two student groups $\left(\chi^{2}=0.58, \mathrm{p}=0.445\right)$.

The numbers (and percentages) of the preclinical students and clinical students who knew the importance of each component of hand hygiene before the workshop on hand hygiene is shown in Table 1. 
Table 1: The pre-workshop knowledge of preclinical and clinical students $(\mathbf{n}=177)$

\begin{tabular}{|c|c|c|c|c|c|}
\hline \multirow{2}{*}{$\begin{array}{l}\text { Component of hand hygiene } \\
\text { Hands should be washed }\end{array}$} & \multicolumn{2}{|c|}{$\begin{array}{l}\text { Preclinical } \\
\text { students } \\
n=104\end{array}$} & \multicolumn{2}{|c|}{$\begin{array}{l}\text { Clinical } \\
\text { students } \\
\mathrm{n}=73\end{array}$} & \multirow[t]{2}{*}{$\mathrm{p}$ value } \\
\hline & No & $\%$ & No & $\%$ & \\
\hline before having direct contact with patients & 56 & 53.8 & 36 & 49.3 & 0.55 \\
\hline after having direct contact with the patients & 70 & 67.3 & 46 & 63.0 & 0.55 \\
\hline c before clean/ aseptic procedures & 53 & 50.9 & 64 & 87.7 & $<0.001$ \\
\hline $\begin{array}{l}\text { d after contact with body fluid/ excretion/ blood/ mucus } \\
\text { membranes/ non-intact skin/ wound dressings }\end{array}$ & 92 & 88.4 & 69 & 94.5 & 0.17 \\
\hline $\begin{array}{l}\text { e after contact with any object in patient's immediate } \\
\text { surrounding }\end{array}$ & 36 & 34.6 & 20 & 27.39 & 0.31 \\
\hline $\begin{array}{l}\text { f When moving from a contaminated body site to a } \\
\text { Clean body site in the same patient }\end{array}$ & 52 & 50.0 & 23 & 31.50 & 0.01 \\
\hline $\mathrm{g}$ for the correct duration & 22 & 21.2 & 29 & 39.7 & 0.007 \\
\hline
\end{tabular}

Before conducting the workshop, the knowledge of hand hygiene when moving from a contaminated body site to a clean body site in the same patient was significantly better among preclinical students $(p=0.01)$ and the knowledge of hand hygiene before clean/ aseptic procedures was significantly better among clinical students $(\mathrm{p}<0.001)$. Although significantly more clinical students knew the correct duration of hand washing $(\mathrm{p}=0.007)$, the actual number of students in both groups who recognized the need to wash hands for the required duration of 40-60 seconds was very low (22 of 102 preclinical and 29 of 78 clinical students). A large proportion of students in both groups (pre-clinical-71.2\% and clinical$76.7 \%$ ) said they needed further education on hand hygiene.

A workshop on hand hygiene was conducted for 112 medical students (response rate $63.3 \%$ ) which included $68(60.7 \%)$ preclinical students and $44(39.3 \%)$ clinical students (response rates of $65.4 \%$ and $60.3 \%$ respectively). Sixty (88.2\%) of the preclinical students and $41(93.2 \%)$ of the clinical students knew that hand washing is the single most important event in the prevention of hospital acquired infections after participating in the workshop $(\mathrm{p}=0.390)$.

The numbers and percentages of the preclinical students, pre and post workshop differences in the knowledge of hand hygiene are shown in Table 2. 
Table 2: Pre and post workshop difference in knowledge of hand hygiene of pre-clinical students

\begin{tabular}{|c|c|c|c|c|c|c|}
\hline & Component of hand hygiene & $\begin{array}{r}\text { Pre wor } \\
n=1\end{array}$ & hop & $\begin{array}{r}\text { Post wor } \\
n=6\end{array}$ & shop & \\
\hline & Hands should be washed & Number & $\%$ & Number & $\%$ & value \\
\hline a. & before having direct contact with patients & 56 & 53.8 & 53 & 77.9 & 0.001 \\
\hline b. & after having direct contact with the patients & 70 & 67.3 & 54 & 79.4 & 0.08 \\
\hline c. & before clean/ aseptic procedures & 53 & 50.9 & 62 & 91.2 & $<0.001$ \\
\hline d. & $\begin{array}{l}\text { after contact with body fluid/ excretion/ blood/ mucus } \\
\text { membranes/ non-intact skin/ wound dressings }\end{array}$ & 92 & 88.4 & 65 & 95.6 & 0.11 \\
\hline e. & after contact with any object in patient's immediate surrounding & 36 & 34.6 & 48 & 70.6 & $<0.001$ \\
\hline f. & $\begin{array}{l}\text { when moving from a contaminated body site to a clean body site } \\
\text { in the same patient }\end{array}$ & 52 & 50.0 & 49 & 72.1 & $<0.001$ \\
\hline g. & knew the correct duration of hand washing & 22 & 21.1 & 51 & 75.0 & $<0.001$ \\
\hline
\end{tabular}

All the components of hand hygiene improved among the preclinical students after conducting the workshop with statistically significant improvements in all components except b and d. Percentage improvement ranged from $7.2 \%$ to as high as $53.9 \%$.

The numbers and percentages of the clinical students, pre and post workshop differences in the knowledge of hand hygiene are shown in Table 3.

Table 3: Pre and post workshop differences in knowledge of hand hygiene of clinical students

\begin{tabular}{|c|c|c|c|c|c|c|}
\hline & \multirow{2}{*}{$\begin{array}{l}\text { Component of hand hygiene } \\
\text { Hands should be washed }\end{array}$} & \multicolumn{2}{|c|}{$\begin{array}{l}\text { Pre workshop } \\
n=73\end{array}$} & \multicolumn{2}{|c|}{$\begin{array}{l}\text { Post workshop } \\
n=44\end{array}$} & \multirow[t]{2}{*}{$\mathrm{p}$ value } \\
\hline & & Number & $\%$ & Number & $\%$ & \\
\hline a. & $\begin{array}{l}\text { hands should be washed before having direct contact with } \\
\text { patients }\end{array}$ & 36 & 49.5 & 40 & 90.9 & $<0.001$ \\
\hline b. & after having direct contact with the patients & 46 & 63.0 & 39 & 88.6 & 0.003 \\
\hline c. & before clean/ aseptic procedures & 64 & 87.7 & 41 & 93.2 & 0.34 \\
\hline d. & $\begin{array}{l}\text { after contact with body fluid/ excretion/ blood/ mucus } \\
\text { membranes/ non intact skin/ wound dressings }\end{array}$ & 69 & 94.5 & 43 & 97.7 & 0.41 \\
\hline e. & $\begin{array}{l}\text { after contact with any object in patient's immediate } \\
\text { surrounding }\end{array}$ & 20 & 27.4 & 36 & 81.8 & $<0.001$ \\
\hline f. & $\begin{array}{l}\text { If moving from a contaminated body site to a clean body site } \\
\text { in the same patient }\end{array}$ & 23 & 31.5 & 37 & 84.1 & $<0.001$ \\
\hline g. & knew the correct duration of hand washing & 29 & 39.7 & 38 & 86.4 & $<0.001$ \\
\hline
\end{tabular}


All the components of hand hygiene improved among the clinical students after conducting the workshop with statistically significant improvement in components a, b, e, f and g. Percentage improvement ranged from $3.2 \%$ to as high as $54.4 \%$.

\section{Discussion}

Hospital acquired infection is an important global health problem, and hand hygiene is an effective method of infection control. ${ }^{4}$ Recent studies have found low awareness of hand hygiene among medical students and certified HCWs. ${ }^{18-22}$ The present study was aimed to assess the knowledge of hand hygiene among preclinical and clinical students at the Faculty of Medicine, KDU before and after conducting a workshop on hand hygiene.

Although hand hygiene is a simple procedure, the knowledge of hand hygiene among these medical students did not meet the current guidelines set by WHO before conducting the workshop. ${ }^{2}$ It was evident that development of hand hygiene promotion programs would be necessary to improve the hand hygiene of our medical students. There was a significant difference in the pre-workshop knowledge of preclinical and clinical students on hand washing before clean/ aseptic procedures and the duration of hand washing. This difference could be due to the limited clinical experience of pre-clinical students. Interestingly, clinical students had a significantly poorer knowledge than preclinical students on hand washing when moving from a contaminated to a clean body site in the same patient. One possible reason for this could be the lack of role models in the clinical setting.

The workshop on hand hygiene was focused on educating the medical students on preventing HAIs by increasing their awareness and knowledge of hand hygiene compliance. Specifically, the workshop addressed the need to improve education of medical students concerning hand hygiene. This approach used a combination of lectures and practical demonstrations to provide additional instructions on how to prevent HAIs by means of hand hygiene, especially against highly resistant organisms such as methicillin-resistant Staphylococcus aureus.

Statistically significant $(\mathrm{p}<0.05)$ improvements were seen in the preclinical students in all components tested except the need to wash hands after contact with body fluid / bodily excretions / blood / mucus membranes / non-intact skin / wound dressings (components $\mathrm{b}$ and $\mathrm{d}$ in Table 2). This could be due to these students having a high awareness of this component even before the workshop as shown in Table 2. Although significant improvements were seen, the actual percentage of pre-clinical students who were able to correctly identify the need to wash hands was less than $80 \%$ in components a, $\mathrm{b}$, e, $\mathrm{f}$ and $\mathrm{g}$ suggesting that some students may have difficulty in comprehending the importance of these facets of hand hygiene at this stage of their medical career. In contrast, over $80 \%$ knowledge was seen in all components in the clinical group with significant improvement seen in components $\mathrm{a}, \mathrm{b}, \mathrm{e}, \mathrm{f}$ and $\mathrm{g}$. Nonsignificance in components $\mathrm{c}$ and $\mathrm{d}$ was probably due to the high level of knowledge prior to the workshop as shown in Table 3.

A study conducted at the University of Miami Miller School of Medicine, Department of Anesthesiology, Miami, Florida, USA in 2010 concluded that there was a statistically significant improvement of knowledge of hand hygiene among health care workers (nurses, medical students and physicians in ascending order) after conducting an awareness program on hand hygiene. ${ }^{23}$ Another study conducted at the National University Hospital (NUH), Singapore, during the period 2009 to 2012, showed that there was a statistically significant improvement of hand hygiene among nursing students after health 
education by conducting an experimental learning assignment on hand hygiene. ${ }^{24}$ These two studies were based on awareness programs and learning assignments. In the present study, a one-day workshop was conducted which was more expeditious. The knowledge of hand hygiene among medical students before and after conducting a workshop on hand hygiene has not been previously compared.

One limitation of the study was that the post-workshop knowledge was assessed immediately after conducting the workshop on hand hygiene. Assessing the knowledge after a period of time would have given an understanding on how much of knowledge is retained. In addition, only the knowledge of hand hygiene was assessed. An observational assessment would have given a better assessment of the depth of understanding and its translation to actual clinical practice.

Recent global increases in health care associated infection rates suggest that there is a critical need for improved periodic education and training of HCWs concerning hand hygiene. By conducting a workshop on hand hygiene, we were able to achieve an improvement in knowledge of hand hygiene among these medical students.

\section{Conclusions}

A statistically significant improvement of knowledge about hand hygiene among medical students (preclinical and clinical) was observed after conducting a workshop on hand hygiene, which consisted of lectures on hand hygiene and practical demonstrations of hand washing. The importance of educating medical students on hand hygiene and infection prevention and control is highlighted by this study.

Conflicts of Interests: The authors have no conflict of interest

\section{References}

1. Sánchez-Payá J, Bischofberger C, Lizan M, et al. Nosocomial infection surveillance and control: current situation in Spanish hospitals. Journal of Hospital Infection 2009; 72(1):50-56.

doi: 10.1016/j.jhin.2009.01.013.

2. WHO: WHO guidelines for hand hygiene in health care. Geneva: World Health Organization, 2009.

3. Pittet D, Allegranzi B, Sax H, et al. WHO Global patient safety challenge, World Alliance for patient safety. Evidence-based model for hand transmission during patient care and the role of improved practices. Lancet Infectious Diseases 2006; 6(10): 641-652. doi:10.1016/s1473-3099(06)70600-4

4. Mathur P, Hand hygiene: back to the basics of infection control, Indian Journal of Medical Research 2011; 134 (5):611-620. doi: 10.4103/0971-5916.90985.

5. Kelcikova S, Skodova Z, Straka S. Effectiveness of hand hygiene education in a basic nursing school curriculum, Public Health Nursing 2012; 29 (2):152-159. doi: 10.1111/j.1525-1446.2011.00985.x.

6. Cummings LK, Anderson DJ, Kaye KS. Hand hygiene noncompliance and the cost of hospital-acquired Methicillin Resistant Staphylococcus aureus infection. Infection Control and Hospital Epidemiology 2010; 31(4):357-364. doi: 10.1086/651096.

7. Borges LFDA, Rocha LA, Nunes MJ, et al. Low compliance to hand washing program and high nosocomial infection in Brazil Hospital. Inter disciplinary Perspectives on Infectious Diseases 2012; Article ID 579681 doi: 10.1155/2012/579681.

8. Sax H, Allegranzi B, Uçkay I, et al. My five moments for hand hygiene: a user-centred design approach to understand, train, monitor and report hand hygiene. Journal of Hospital Infection 2007; 67 (1):9-21. doi:10.1016/j.jhin.2007.06.004

9. Chou DT, Achan P, Ramachandran M. The World Health Organization '5 moments of hand hygiene': the scientific foundation. Journal of Bone Joint Surgery 2012; 94(4):441-445. doi:10.1302/0301$620 X .94 B 4.27772$. 
10. Al Kadi A, Salati SA. Hand hygiene practices among medical students. Inter disciplinary Perspectives on Infectious Diseases 2012; Article ID 679129 doi:10.1155/2012/679129

11. Ergin A, Bostanci M, Onal O, et al. Valuation of students' social hand washing knowledge, practices and skills in a university setting. Central European Journal of Public Health 2011; 19 (4):222-226. PMID:22432398

12. Graf K, Chaberny F, Vonberg RP. Beliefs about hand hygiene: A survey in medical students in their first clinical year, American Journal of Infection Control 2011; 39 (10):885-888. doi: 10.1016/j.ajic.2010.08.025.

13. Buerhaus PI, Auerbach DI, Staiger DO. Recent trends in the registered nurse labor market in the U.S.: short-run swings on top of long-term trends. Nursing Economics2007; 25 (2): 59-66. PMID:17500490

14. Abualrub RF. Nursing shortage in Jordan: what is the solution? Journal of Professional Nursing 2007; 23 (2): 117-120. doi:10.1016/j.profnurs.2006.07.008

15. Anwar MA, Rabbi S, Masroor M, et al. Self-reported practices of hand hygiene among the trainees of a teaching hospital in a resource limited country. J Pakistan Med Assoc 2009; 59(9):631-634. PMID: 19750862

16. Patarakul K, Tan-Khum A, Kanha S, et al. Cross-sectional survey of hand-hygiene compliance and attitudes of health care workers and visitors in the intensive care units at King Chulalongkorn Memorial Hospital. J Med Assoc Thai 2005; 88; Suppl 4:S287-93 PMID:16623043

17. World Alliance for Patient Safety. WHO guidelines on hand hygiene in health care advanced draft a Summary: Clean hands are safer hands.

Available at http://whqlibdoc.who.int/hq/2005/WHO_EIP_SPO_QPS_05.2.pdf; Accessed September 16, 2014.

18. Qushmaq IA, Heels-Ansdell D, Cook DJ, et al. Hand hygiene in the intensive care unit: prospective observations of clinical practice. Pol Arch Med Wewn 2008; 118(10) 543-7. PMID:19112814

19. Bukhari SZ, Hussain WM, Banjar A, et al. Hand hygiene compliance rate among healthcare professionals, Saudi MedJ2011 May; 32 (5):515-9. PMID:21556474

20. Basurrah M, Madani T: Hand washing and gloving practice among health care workers in medical and surgical wards in a tertiary care centre in Riyadh, Saudi Arabia. Scand J Infect Dis 2006; 38 (8): 620-624. doi: $10.1080 / 00365540600617025$

21. Duroy E, Le Coutour X: Hospital hygiene and medical students. Med Mal Infect 2010; 40 (9):530-536. doi: 10.1016/j.medmal.2010.02.010.

22. Feather A, Stone SP, Wessier A, et al. 'Now please wash your hands': the hand washing behaviour of final MBBS candidates. Journal of Hospital Infection 2000; 45 (1):62-64. DOI:10.1053/jhin.1999.0705

23. Fitzpatrick M, Everett-Thomas R, Shekhter NI, et al.A novel educational programme to improve knowledge regarding health care-associated infection and hand hygiene. International Journal of Nursing Practice 2011; 17(3):269-274. doi: 10.1111/j.1440-172X.2011.01934.x.

24. Salmon S, Wang XB, Seetoh T, et al. A novel approach to improve hand hygiene compliance of student nurses. Antimicrobial Resistance and Infection Control 2013; 2 (16):1-5. doi: 10.1186/2047-2994-2-16. 